"Crowdsourcing benefits in postgraduate project supervision: Sefako Makgatho Health Sciences University statistics and computer science case study"

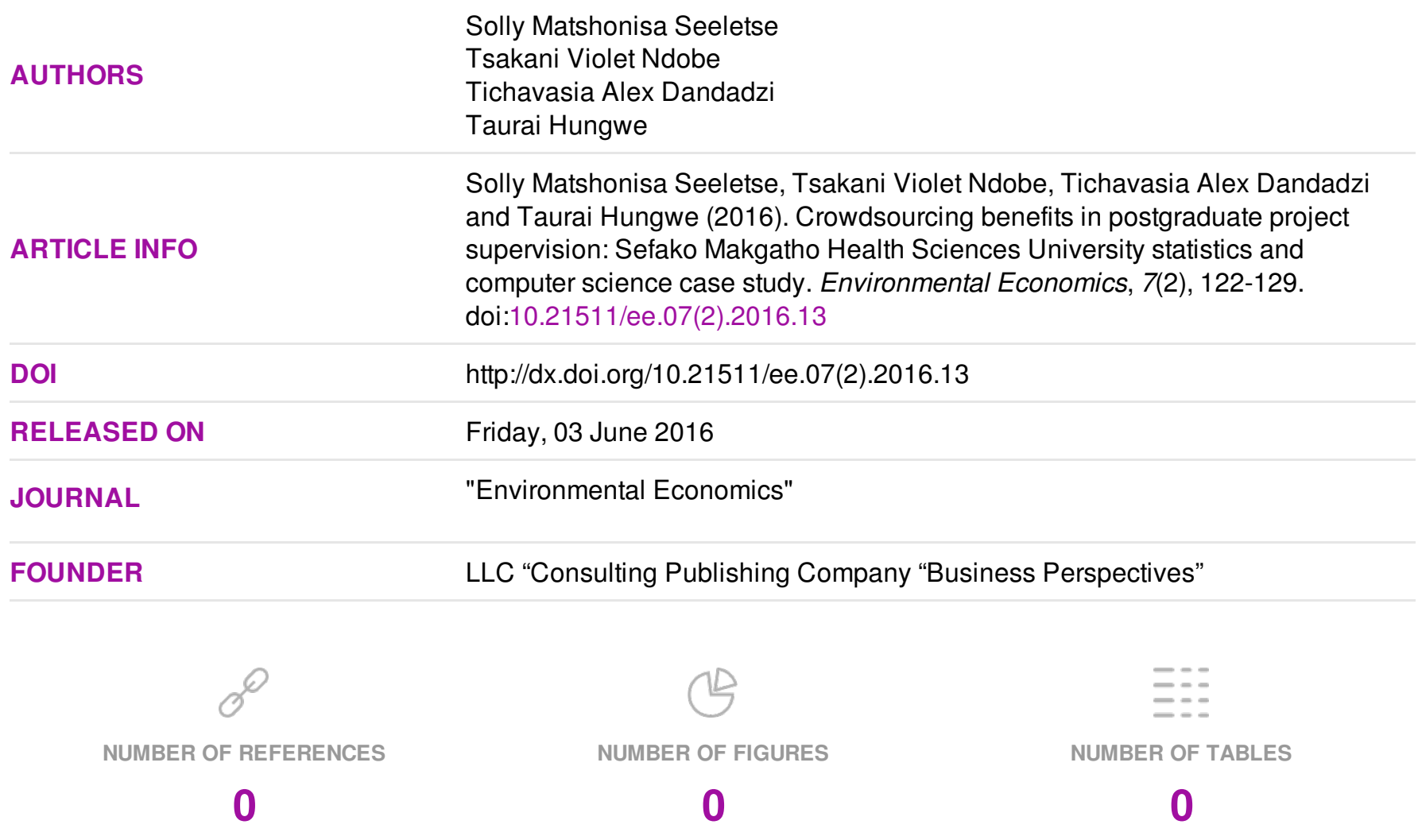

(C) The author(s) 2022. This publication is an open access article. 
Solly Matshonisa Seeletse (South Africa), Tsakani Violet Ndobe (South Africa), Tichavasia Alex Dandadzi (South Africa), Taurai Hungwe (South Africa)

\title{
Crowdsourcing benefits in postgraduate project supervision: Sefako Makgatho Health Sciences University statistics and computer science case study
}

\begin{abstract}
The paper reports on the findings made on an experiential exercise of Bachelor of Science Honours in Statistics (BSc Hons Stat) in the Department of Statistics and Operations Research (SOR) of the Sefako Makgatho Health Sciences University (SMU) in South Africa. SOR is a small, understaffed department, which offers courses for degrees from Bachelor to Doctoral levels in the subfields of Artificial Intelligence, Data Mining, Operations Research, Statistics and related ones. On SMU campus, expertize in some of these fields is also available in the Department of Computer Science (DCS). In the 2015 academic year SOR admitted 20 BSc Hons Stat students beyond its staffing capacity. Then, SOR invited DCS in a crowdsourcing initiative to jointly supervise student projects in the various subfields mentioned. The challenges include conflict and limited experience. These are managed satisfactorily though, but mainly because they occurr at low levels. This crowdsourcing arrangement nevertheless results in timely submissions of final projects, improved quality projects worthy of being published, innovation, quality teamwork, and some synergistic outcomes. Coordinators also learn and/or improved some project management skills.
\end{abstract}

Keywords: conflict, crowdsourcing, innovation, optimization, synergy, teamwork.

JEL Classification: D7, I21, I23, I26, L3, O3.

\section{Introduction}

The utilization of multitudes of partners to enhance quality in work has become fashionable, justifiably so because of the value that many intellects add to work. Agrawal, Christiana and Avi (2014) point out that a prudent use of crowds can assist to improve economies. Such a valuable platform is known as crowdsourcing (Saxton \& Kishore, 2013). Many experiences exist as a result of cases where departments that are understaffed source crowds (such as part-time staff) to ensure that quality work is done. Many people assist in covering more sections that require attention. However, Lukyanenko, Parsons and Wiersma (2014) enlighten that involvement of more intellectuals, who are prepared to contribute to scholarly chattels, can elevate efficiency in the tasks to be performed. While working in silos can yield some benefits, there is usually more to come from work that is performed by more than one person. According to Brabham (2012a), participation in cases where more than one person stands to benefit is an incentive for unselfish people willing to share. Crowdsourcing benefits also apply to distance inte-

(C) Solly Matshonisa Seeletse, Tsakani Violet Ndobe, Tichavasia Alex Dandadzi, Taurai Hungwe, 2016.

Solly Matshonisa Seeletse, Ph.D., DBA, Professor, Department of Statistics and Operations Research, Sefako Makgatho Health Sciences University, South Africa.

Tsakani Violet Ndobe, Lecturer, Department of Computer Science, Sefako Makgatho Health Sciences University, South Africa.

Tichavasia Alex Dandadzi, Ph.D., Head of Department, Department of Computer Science, Sefako Makgatho Health Sciences University, South Africa.

Taurai Hungwe, Lecturer, Department of Computer Science, Sefako Makgatho Health Sciences University, South Africa. racting such as computer networking. Afuah and Tucci (2012) explain that crowdsourcing can provide solutions when distant searches are made. The communication can be extended to find associates, connections and networking partners through connections that are performed on technological communications.

This paper discusses the manner in which crowdsourcing was applied in the 2015 academic year in postgraduate student supervision in the SOR. It also explains the benefits achieved compared to when there was no crowdsourcing, as well as some possible conflicts.

\section{Crowdsourcing}

Crowdsourcing is a thoughtful process of getting work done from a crowd of people. It entails the process of locating needed services, ideas, or content by soliciting contributions from a large group of people (Estellés-Arolas \& González-Ladrón-deGuevara, 2012). This mode of sourcing is often used to divide work between participants by combining the efforts of several willing individuals, where each contributor adds a contribution that may combine with those of others to achieve a greater result. Henceforth, the work may come from an undefined public, rather than being commissioned from a specific, named group. Also, crowdsourcing includes a mix of bottom-up and top-down processes (Brabham, 2010). Substantial benefits of crowdsourcing include cost saving, speed, quality, flexibility, scalability, and diversity. It basically refers to a wide range of activities, providing different benefits for its organizers (Brabham, 2013). In innovation, it enables organiza- 
tions to learn beyond the employees' capabilities. The main purpose for using crowdsourcing is to engage a group for a common goal, such as innovation, problem solving and efficiency.

Prpić and Shukla (2016) infer that most frequently mentioned motives of users, participating in crowdsourcing, are money, philanthropy, fun, reputation, attention, and knowledge. Both intrinsic and extrinsic motivations influence decisions to participate in crowdsourcing.

Crowdsourcing is not a straightforward exercise without challenges. For example, unqualified participants in crowdsourcing can lead to unusable contributions. This can lead to lowering of quality. Ensuing drawbacks can be discontent when individuals' inputs are not included in the work. Time is also wasted when unusable contributions are made (Brabham, 2008; 2012b). Therefore, there should be a robust monitoring, evaluation, and corrective action in instances where some crowdsourcing participants may want to sabotage the efforts of others. Also, crowdsourcing may be used unethically by people who would benefit at the expense of others, without giving due acknowledgements to every participant (Busarovs, 2013).

Mercuse (2011) enlightens that crowdsourcing has some positive elements of a cooperative. Such positive elements of crowdsourcing include access to new ideas and solutions, deeper consumer engagement, opportunities for cocreation, tasks optimization, and reduced costs, among others. A cooperative is a sovereign association of people willingly uniting to work towards achieving common economic, social, and cultural needs and aspirations through a jointly owned and democratically controlled business venture (Dana, 2010). The definition assumes that ethical guidelines and legal compliance would have been accounted for. This means that even though crowdsourcing functions innovatively, relevant guideposts would enclose the applicable policies, procedures and operations.

1.1. Teamwork. Teamwork is a vital component for business. It is essential for groups of colleagues to work together in order to achieve a goal (Cattani et al., 2013). Team members should cooperate with complementary backgrounds using individual skills and providing constructive feedback despite any personal conflicts between individuals. According to West (2012), three categories of teamwork exist. These are transition process (TP), action process (AP) and interpersonal process (IP). Each category has several processes within it, which together result in 10 processes. TP consists of mission analysis, goal description and strategy development. AP en- tails monitoring progress towards goals, systems monitoring, team monitoring and background behavior as well as coordination. IP entails conflict management, motivation and confidence building, as well as affective management. Teamwork is generally effective when team members have experience working together due to enhanced coordination and communication (De Church \& Mesmer-Magnus, 2010). Some cases require team members to be trained to improve teamwork.

Hoegl and Gemuenden (2001) outline some few important teamwork benefits. One benefit is problem solving from contributions of collaborators who can provide alternative approaches to a solution. Another benefit is networking and developing relationships. Moreover, a team working together continually can develop high level of bonding to help avoidance of unnecessary conflicts. Unique qualities of each individual enable unique knowledge and abilities contributing to improved team members.

Caution is that teamwork is not necessarily easy to administer. It is also not a guarantee for success. Members in a team should all be worthy for the tasks at hand. Teamwork can have adverse effects if not perfectly administered (Lattimore \& Von Glinow, 2010). It may have an unforeseen upshot of inciting hostility toward the managerial goal of making the teams fully self-managing. Also, teamwork initiatives may have a potential of individuals doing less work in a team than what they would normally do working individually (known as social loafing). Several measures are available for offsetting social loafing (Prpić, Taeihagh \& Melton, 2015). Management can minimize social loafing by introducing incentives and rewards. They have to make individual performance to be visible while in a team setting. They can form smaller teams of specialization in specific tasks to certain individuals, and then measure individual performance. Social loafing can also be reduced by increasing employee motivation, by selecting motivated employees, and increasing job enrichment.

1.2. Synergy. Synergy refers to the use of several elements to generate a whole that is greater than the sum of the individual portions (Goffee \& Jones, 2013). In teamwork and in crowdsourcing, the synergistic relationship can be identified from the various crowd or team members (Gillwald, Moyo \& Stork, 2012). The synergistic action gives different dimensions to competitiveness, strategy and network identity becoming an unconventional 'weapon' to compete in the market. It is used by those who exploit the economic systems' potential in depth. Synergy constitutes a model of the factors which enable the practitioners to outline an active synergistic net- 
work. Furthermore, according to Hertzberg and MacDonell (2002), the synergistic network signifies an incorporated fragment of the system which controls, coordinates and optimizes functions.

1.3. Innovations. Innovation refers to development of new, original and more effective ideas and mechanisms that lead to better solutions which meet new requirements, unarticulated needs, or existing market needs (Heyne, Boettke \& Prychitko, 2010). Durable thinkers reflect more effective products, processes, services, technologies and business models that improve work. In the work environment, innovation often leads to more productivity, improved performance, better results, and cost-effectiveness, among others. Innovation can be a catalyst to growth. Furthermore, it continually modernizes the organizational structure with better and more effective processes and products. Innovators continuously search for superior techniques to satisfy their work with improved quality, durability, service, and price with advanced technologies and organizational strategies.

According to Siltala (2010), innovation is the precise utility by which innovators either produce novel treasure generating capitals, or provide current assets with enhanced prospects for generating prosperity. Innovation is about change (or improvement), which occurs because of an acknowledged necessity. It is carried out mainly by competent people with relevant technologies. Even though some of the innovations do not require finances, many sophisticated ones may require financial support.

Even though innovation can be accomplished in several ways, Frankelius (2009) points out that research and development is a formal direct approach to initiate innovation. Information technology also influences innovation. These approaches initiate radical and revolutionary innovations. However, innovations can also be established by informal on-the-job variations of practice, through discussion and blend of professional experience and by other countless methods. Changing business processes and management style can also lead to a work climate that is conducive to innovation. Thus, deliberate and unintentional processes are capable of effecting innovation, but wisdom is a necessary attribute to acknowledge and recognize innovative opportunities. Crowdsourcing is a deliberate and intelligent way to innovate and to ensure attainment of quality work.

Innovators produce innovations to ultimately substitute older mechanisms. Distribution of innovation from an innovating party to other parties occurs to assist and help networking groups (Tuomi, 2002). Other parties may advance the innovation by addi- tional or elevated innovation. Effectiveness of innovation should be gauged. Ideally, innovation should produce positive impact. The innovation measures at the organizational level relays to individuals, team-level assessments, and private companies from the smallest to the largest company. They can be conducted through surveys, workshops, consultants, or internal benchmarking. According to Salge and Vera (2012), a balance scorecard is a common innovation gauging tool in organizations. Today there is no established general way to measure organizational innovation. Often, each company or industry uses ad hoc measures for this purpose.

1.4. Conflict in crowdsourcing. Conflict occurs when there is a serious disagreement or argument in which parties get into collision or disagreement in contradicting one another (Maccoby \& Scudder, 2011). It exists in all organizations, and may sometimes designate a healthy exchange of ideas and creativity. Some positive criticism of management may be a form of conflict. However, counterproductive conflict can result in delays and/or disruptions of work. It is important to manage conflict. It is the role of executive directors and/or managers to gauge the level and possible impacts of conflict (Lang, 2009). Resolving conflict should ideally occur at the levels where it occurs. The problems may occur when conflict gets out of hand. There are many causes of conflict and many forms, which mainly depend on the size and format of an organization or the industry. Fisher (2010) advises that conflict should not be escalated to beyond manageable levels. At the time that conflict prospects appear, they should be thwarted. According to Ishak and Ballard (2012), even when conflict has already started to frustrate operations, the affected company should find ways to regroup and refocus. Counterproductive conflict is a source of weakness in an organization. It can also be a threat in the company transforming to be reality. Hence, crowdsourcing approach should apply robust methods to curb negative influences of occurring conflict.

1.5. Task optimization. The presence of distractors in crowdsourcing cannot be completely ruled out, such as conflict and other threats. In order to obtain the best from crowdsourcing, methods and processes should be systematic and robust in order to enable optimal crowdsourcing activity. Optimization refers to an act, process, or methodology of making a system as effusively impeccable, functional, or effective as possible (Babulall, 2012). It also refers to allocation of resources in order to achieve certain performance and quality goals. Innovation initiatives are aimed at optimizing the tasks and their outcomes. The use of a crowd is aimed at 
maximizing benefits and minimizing possible detriments. Unsuitable fragments are not included in the solution (Savulescu \& Persson, 2012). Teamwork is also applied for ideas to eliminate fragile solution proposals and reinforce useful ones. These show that optimization can easily be accomplished through innovation that is driven by crowdsourcing and meaningful teamwork.

1.6. More reflections on crowdsourcing. For a crowdsourcing application to work beneficially, certain concerns in its development are necessary. The number in a crowd should be at least three people as, by implication, two people for crowdsourcing are often inadequate (Stol \& Fitzgerald, 2014). Also, the members should not be superfluously too many. Crowdsourcing may be applied in addressing basic tasks. However, according to Greengard (2011), for crowdsourcing to yield maximum benefits, it is mainly recommended to address complex problems in multifaceted contexts. It is beneficial in crisis situations, knowledge-intensive tasks, and multi-disciplinary problem settings, among others (Erickson, Petrick \& Trauth, 2012). As may have been implied, crowdsourcing benefits are not limited to coordination, communication, knowledge, motivation, planning and quality assurance. The benefits extend to task decomposition (which can apply in complex and dynamic cases), intellectual property ownership, remuneration, scheduling and others as may be customised in specific situations (Tajedin \& Nevo, 2013). Care should be taken that crowdsourcing is not wasted where it does not add value. Duplicate resourcing should be avoided. If some members cannot make a meaningful contribution, they should be removed. According to several authors (Chandler \& Kapelner, 2013; Erickson, 2012; Erickson, Petrick \& Trauth, 2012; Ipeirotis, 2010; Savage, 2012), a crowd should be leveraged only in cases where it can be a source of innovation and increased wisdom for the participants.

\section{Setting}

The cooperation between SOR and DCS of the Sefako Makgatho Health Sciences University (SMU) has been demonstrable since 2008, and is durable. Activities among members of DCS and SOR take place regularly. DCS and SOR occasionally work together on same academic projects. In 2015, a new head of SOR was appointed. He knew about the desired plan of the DCS to admit 30 students for the BSc Honours (BSc Hons) degree in Computer Science (Comp Sc) during that year. Due to incomplete processes, BSc Hons in Comp Sc could not be offered. Then, some students who had applied to the BSc Comp Sc applied to enrol for BSc Hons Stat, which was their second major for the BSc degree.
SOR then admitted 20 students for enrolling in the BSc Hons Stat, despite having capacity to supervise only eight (8) BSc Hons students in Stats. The 20 admitted students exceeded SOR capacity by 12 . The previous highest enrolment requiring project supervision was 11 . Thus, 12 in excess of the initial target, which SOR had planned to admit, required a supervisor staffing supplement due to a project module requiring supervision. The project module leads to limiting admission of BSc Hons Stat students because each student should be allocated a supervisor. Hence, 20 students needed more academics to supervise their projects.Then members of the DCS were "crowd sourced 'with Stats ones to assist with project supervision. Moreover, there had never been a $100 \%$ pass in Stats projects since a project was introduced in the Hons curriculum. Also, extensions had to be given for some submissions of the projects in the past.

The Heads of Departments (HoDs) of the two departments (DCS and SOR) discussed the issue of cosupervision of research projects. The DCS offered its assistance where students wanted to undertake projects that would contain a computer science application. Eleven (11) members from both teams and other independent SMU divisions were also involved in the crowdsourcing. Four (4) were sourced from DCS, five (5) from SOR, and one (1) from Research Directorate and Health Sciences teaching Statistical Methods.

Supervisors from the crowdsourcing team were assigned to students with Comp Sc majors who had initially wanted to enrol for BSc Hons Comp Sc, because DCS had not secured accreditation for its BSc Hons program. Two coordinators were appointed for supervision purposes, one for the Comp Sc students and another for the Stats group.

\section{Method}

The research was conducted in a crowdsourcing experiential exercise in SOR. The research population was all the 11 crowdsourcing members described earlier. A census of all these members was used in the study, since the population number was small. The reason to choose them was based on the desire to capture reality and ensure the authority of the study. Their activities and impacts of those activities were of interest to this study. The data collection was made in two ways. First, it was the retrospective records of past methods and results of the supervision of the BSc Hons Stat students. The second was through the coordinators by recording the actual occurrences as they happened. Data analysis consisted of comparative analyses of previous years' occurrences, covering problems and chal- 
lenges experienced in the processes. The comparison stretched to identify past problems and prospects. The problems and prospects were then compared with new ones. At the analysis stage, a conscious comparison with the basic concepts of crowdsourcing was also made.

\section{Results}

The exercise which started with few resources in a scarce skill was undertaken by a team from two vital skills in the modern economy, which are computer science and statistics. The supervision process produced passes in projects of all the 20 students. Timeous submissions and passes in all the projects were realised. Thus, crowdsourcing managed to offset possible risks set by limited resources and limited skills.

The coordinators faced challenges emanating from the supervisory arrangements. Students supervised in DCS felt they were overworked as compared to those in SOR. The former group were required to develop a working software system in addition to the Stats requirement.

The crowdsourcing benefit was utilized in order to curb escalation and recurrence of the possible problems. Also, negotiations were sometimes included in enticing continued work. The different approaches of the coordinators also assisted in synergies for managing somewhat volatile situations during the supervision year.

Passes in all the projects were realized by year end. This level of achievement had never happened before. Thus, according to the results, students were satisfied with the actual project outcomes, albeit some dissatisfactions with the level at which the marks were allocated. Some students felt they deserved higher marks than what they had been awarded. This could not bother the crowdsourcing team because moderators and internal examiners had independently awarded consistent marks for the projects.

There was no doubt that the output rate of crowdsourcing in the exercise was satisfactory, because all the students had passed. Furthermore, there were some projects that impressed examiners and the external examiners. These projects eventually produced journal articles. These published works are, therefore, adequate evidence of quality output.

The model adopted in 2015 for supervision was not necessarily supported by the management of faculty. Fortunately, it was eventually successful. Also, there were no effective delays in meeting the time targets for submission since all the students managed to submit complete projects. This was the first time since 2009 (the year in which the projects were introduced in the BSc Hons curriculum) that all the students could submit in time. In the 2015 crowdsourcing year, all the students managed to do research, met most due dates and, finally, met the final submission date for examination. Furthermore, all the satisfied projects pass requirements, including passes with merit in a few of them.

Crowdsourcing during that year also became an effective communication tool. This coordination for BSc Hons Stat supervision enabled effective communication among the participants. It also helped to improve communication of the submission dates and the virtues of the arrangement made for student supervision.

It was also observed that coordination in the crowdsourcing engagement came out credibly loftier. There were evidences and indications of close working relationships among students, coordinators, and supervisors.

In addition, compared to past years, there were closer collaborations between the students and their supervisors, among different students and among different supervisors. These collaborations elevated competition for more worthy research.

The other benefit mainly from the coordinators in the crowdsourcing experience was the level of awareness of the various committees and bodies on campus (such as research and ethics committees) that approve the proposed studies. The students were always updated on matters relating to their studies, their research progress was tracked, they were being monitored for meeting the deadlines, and there was a proper and effective control of the research processes.

The relationships from the crowdsourcing experiences of staff and students also opened avenues for future collaboration. Evidence of this exists by the fact that some members from the two departments formed networks of collaborations in undertaking some research projects together. These relationships have thus far shown to increase research output for the two departments involved.

The points made show that despite the challenges encountered, the crowdsourcing produced more benefits than without crowdsourcing. Hence, crowdsourcing added value to the SOR academic and research activities. Challenges that were encountered were minimal and ineffective in derailing the targets of completed research.

The Comp Sc researches combined Stats with artificial intelligence, which was a collaboration of Stats with technology (de Vreede et al., 2013). While the 
resultant standards were high in the applications of Stats on these projects, incorporation of technology certainly increased the worth/value of the outcomes accomplished. There was therefore task maximization in the crowdsourcing supervision.

Another important benefit happened at the coordinator's level. Though unplanned, the coordinators received on-the-job training in applied project management, which is a methodical approach to planning and guiding project processes from start to finish (Wysocki, 2013). According to Serra and Kunc (2015), the processes are guided through five stages of initiation, planning, executing, controlling and closing. The level at which the coordinators performed also demonstrated the four last of the five stages of project management.

The challenges in the crowdsourcing included limited experiences among some supervisors, and some unwillingness to participate optimally, among others. These were, however, mitigated by continuous mentoring of the inexperienced supervisors, and in some cases introducing co-supervision with the experienced ones. Some initial challenges were turned into network opportunities. The challenges that came out were minimal and easy to offset. More difficult challenges could probably have been more difficult to manage.

\section{Discussion}

The crowdsourcing approach in student supervision was able to offset the possible bad effects of limited resources and limited expertise. It also led to client satisfaction as evidenced by the satisfied students. The rate of output showed to outperform all the previous supervision exercises of the past years. The fact that research articles came out of the researches of that crowdsourcing is also an indication of improved or high quality in the outputs from the crowdsourcing initiative. According to the results, time targets were also met by every student involved in that year. There were awareness crusades on a regular basis from the coordinators. Future collaborations seemed to be founded in the exercise. Furthermore, collaboration, communication and coordination also improved during the crowdsourcing period.

The collaboration, communication and coordination attributes also enabled teamwork in the supervision. The evidence of teamwork prevailed. Some synergies emerged, which came from combining Stats concepts with Comp Sc applications. The crowdsourcing was an innovation which yielded benefits, as the tasks were optimized. Therefore, crowdsourcing, despite having some challenges, has great prospects to add value to work.
The challenges that arose, which were supervisor inexperience and emergent conflict, could be managed by other members of the crowd. In case of lack of experience, there were more back up of experience to support the few inexperienced supervisors. Also, the inexperienced ones were learning quickly, which gave the crowdsourcing team an advantage. The conflict that emerged was also of a less magnitude than the engagement of progress. There are signs that if there were higher dimensions of these challenges, it would be very difficult to curb or manage them.

\section{Recommendations}

The following recommendations are made:

- Higher education institutions (HEIs) should encourage, support and sponsor research support crowdsourcing initiatives in order to enhance research outputs.

- Each crowdsourcing engagement should have a definite objectives and clear cut-off date.

- It should ensure that each participant will add value to the engagement.

- It should be sized properly (the number of people in the crowd should be small enough to be manageable, but large enough to cover all the task requirements).

- Crowdsourcing should be applied in academic cases where synergies are created.

- Precautionary measures for possible conflict should be put in place in any crowdsourcing.

\section{Conclusion}

Benefits of crowdsourcing are enormous. In HEIs, there should be policy guidelines that enable crowdsourcing and other partnerships where academic synergies can emerge. Empirical evidence shows that crowdsourcing can reduce sluggishness, as various team members encourage one another to perform. Also, the coordination compels everyone to perform. Certain safety measures are needed in order to circumvent possible conflict, such as those shown in the exercise. The model of crowdsourcing in the study can be a useful benchmark in other applications on SMU campus and in student supervision of other HEI when necessary and applicable. However, the paper does not claim to be generalizable to other environments.

\section{Acknowledgement}

The authors acknowledge the support given by the Departments of Computer Science and Statistics \& Operations Research, as well as the various players who took part in the programs used for the experiential study for this paper. 


\section{References}

1. Afuah, A. \& Tucci, C.L. (2012). Crowdsourcing as a solution to distant search, Academy of Management Review, 37(3), pp. 355-375.

2. Agrawal, A., Christian C. \& Avi, G. (2014). Some simple economics of crowdfunding, National Bureau of Economic Research, pp. 63-97.

3. Babulall, N. (2012). An investigation into business process optimisation at a private bank in South Africa, MBA dissertation. Management College of Southern Africa, Durban, South Africa.

4. Brabham, D.C. (2008). Crowdsourcing as a model for problem solving an introduction and cases convergence, The International Journal of Research into New Media Technologies, 14(1), pp. 75-90.

5. Brabham, D.C. (2010). Moving the crowd at threadless: motivations for participation in a crowdsourcing application, Information, Communication \& Society, 13, pp. 1122-1145.

6. Brabham, D.C. (2012a). Motivations for participation in a crowdsourcing application to improve public engagement in transit planning, Journal of Applied Communication Research, 40, pp. 307-328.

7. Brabham, D.C. (2012b). The myth of amateur crowds: A critical discourse analysis of crowdsourcing coverage, Information, Communication \& Society, 15, pp. 394-410.

8. Brabham, D.C. (2013). Crowdsourcing. London: The MIT Press.

9. Busarovs, A. (2013). Ethical aspects of crowdsourcing, or is it a modern form of exploitation, International Journal of Economics \& Business Administration, 1(1), pp. 3-14.

10. Cattani, G., Ferriani, S., Marianiz, M.M. \& Mengoli, S (2013). Tackling the 'Galácticos' effect: team familiarity and the performance of star-studded projects, Industrial and Corporate Change, 22(6), pp. 1629-1662.

11. Chandler, D. \& Kapelner, A. (2013). Breaking monotony with meaning: Motivation in crowdsourcing markets, Journal of Economic Behavior \& Organization, 90, pp. 123-133.

12. Chin, R. (2015). Examining teamwork and leadership in the fields of public administration, leadership and management. Team Performance Management.

13. Dana, L.P. (2010). Nunavik, Arctic Quebec: where co-operatives supplement entrepreneurship, Global Business and Economics Review, 12(1/2), pp. 42-71, January.

14. De Church, L.A. \& Mesmer-Magnus, J.R. (2010).The cognitive underpinnings of effective teamwork: a metaanalysis, Journal of Applied Psychology, 95(1), pp. 32-53.

15. de Vreede, T., Nguyen, C., de Vreede, G.J., Boughzala, I., Oh, O. \& Reiter-Palmon, R. (2013). A theoretical model of user engagement in crowdsourcing: in collaboration and technology (pp. 94-109). Berlin Heidelberg: Springer.

16. Erickson, L.B. (2012). Leveraging the crowd as a source of innovation: Does crowdsourcing represent a new model for product and service innovation? Proc. SIGMIS Computers and People Research. ACM.

17. Erickson, L.B., Petrick, I. \& Trauth, E.M. (2012). Organizational uses of the crowd: developing a framework for the study of crowdsourcing. Proc. SIGMIS Computer and People Research, ACM.

18. Estellés-Arolas, E. \& González-Ladrón-de-Guevara, F. (2012). Towards an integrated crowdsourcing definition, Journal of Information Science, 38(2), pp. 189-200.

19. Fisher, N. (2010). A better way to manage conflict, Political Quarterly, 81(3), pp. 428-430.

20. Frankelius, P. (2009). Questioning two myths in innovation literature, Journal of High Technology Management Research, 20(1), pp. 40-51.

21. Gillwald, A., Moyo, M. \& Stork, C. (2012). Understanding what is happening in ICT in South Africa. Cape Town: Research ICT Africa.

22. Goffee, R. \& Jones, G. (2013). Creating the best workplace on the Earth. Harvard Business Review, pp. 99-106.

23. Greengard, S. (2011). Following the crowd, Communications of the ACM, 54(2), pp. 20-22.

24. Hertzberg, R.C. \& MacDonell, M.M. (2002). Synergy and other ineffective mixture risk definitions, Science of The Total Environment, 288, pp. 31-42.

25. Heyne, P., Boettke, P.J. \& Prychitko, D.L. (2010). The economic way of thinking, $12^{\text {th }}$ edition. Prentice Hall.

26. Hoegl, M. \& Gemuenden, H.G. (2001). Teamwork quality and the success of innovative projects: a theoretical concept and empirical evidence, Organization Science, 12(4), pp. 435-449.

27. Ipeirotis, P.G. (2010). Analyzing the Amazon Mechanical Turk marketplace, XRDS, 17(2), pp. 16-21.

28. Ishak, A.W. \& Ballard, D.I. (2012). Time to re-group: a typology and nested phase model for action teams, Small Group Research, 43(1), pp. 3-29.

29. Lang, M. (2009). Conflict management: a gap in business education curricula, Journal of Education for Business, 84(4), pp. 240-245.

30. Lattimore, M.S. \& Von Glinow, M.A.Y. (2010). Organizational behavior: Emerging knowledge and practice for the real world, $5^{\text {th }}$ edition. Boston: McGraw-Hill Irwin.

31. Lukyanenko, R., Parsons, J. \& Wiersma, Y. (2014). The IQ of the crowd: Understanding and improving information quality in structured user-generated conten, Information Systems Research, 25(4), pp. 669-689.

32. Maccoby, M. \& Scudder, T. (2011). Leading in the heat of conflict, Training and Development, 65, pp. 46-51.

33. Mercuse, P. (2011). Cities for people, not for profit. New York: Routledge.

34. Prpić, J.\& Shukla, P. (2016). Crowd science: Measurements, models, and methods. In Proceedings of the $49^{\text {th }}$ Annual Hawaii International Conference on System Sciences, Kauai, Hawaii: IEEE Computer Society. 
35. Prpić, J., Taeihagh, A. \& Melton, J. (2015). The fundamentals of policy crowdsourcing. Policy \& Internet, 7(3), pp. 340-361, September.

36. Savulescu, J. \& Persson, I. (2012). Unfit for the future: The urgent need for moral enhancement. Oxford: Oxford University Press.

37. Salge, T.O. \& Vera, A. (2012). Benefiting from public sector innovation: the moderating role of customer and learning orientation, Public Administration Review, 72(4), pp. 550-560.

38. Savage, N. (2012). Gaining wisdom from crowds, Communications of the ACM, 55(3), pp. 13-15.

39. Saxton, O. \& Kishore, R. (2013). Rules of crowdsourcing: models, issues, and systems of control, Information Systems Management, 30, pp. 2-20.

40. Serra, C.E.M. \& Kunc, M. (2015). Benefits realisation management and its influence on project success and on the execution of business strategies, International Journal of Project Management, 33(1), pp. 53-66.

41. Siltala, R. (2010). Innovativity and cooperative learning in business life and teaching. Turku: University of Turku.

42. Stol, K.-J. \& Fitzgerald, B. (2014). Two's company, three's a crowd: a case study of crowdsourcing software development, in: Pro. $36^{\text {th }}$ International Conference on Software Engineering, Hyderabad, India.

43. Tajedin, H. \& Nevo, D. (2013). Determinants of success in crowdsourcing software development, Proc. SIGMIS Computer and People Research, Cincinnati, OH, USA.

44. Tuomi, I. (2002). Networks of innovation. Oxford: Oxford University Press.

45. West, M. (2012). Effective teamwork: practical lessons from organizational research. Chichester, West Sussex, UK: BPS Blackwell.

46. Wysocki, R.K. (2013). Effective project management: Traditional, adaptive, extreme, $7^{\text {th }}$ edition. New York: Wiley. 